\title{
Risk Factors for Acute Myocardial Infarction During the Postoperative Period of Myocardial Revascularization
}

\author{
José Ribamar Costa Jr., Dinaldo C. Oliveira, Alexei DerBedrossian, Enilton T. Egito, \\ Edson R. Romano, Marcos O. Barbosa, leda M. Liguori, Jorge Fahran, Luis C. B. Souza, \\ Adib D. Jatene, Leopoldo S. Piegas
}

São Paulo, SP - Brazil

Objective - To identify risk factors for acute myocardial infarction during the postoperative period after myocardial revascularization.

Methods - This was a case-control study paired for sex, age, number, type of graft used, coronary endarterectomy, type of myocardial protection, and use of extracorporeal circulation. We assessed 178 patients (89 patients in each group) undergoing myocardial revascularization, and the following variables were considered: dyslipidemia, systemic hypertension, smoking, diabetes mellitus, previous myocardial revascularization surgery, previous coronary angioplasty, and acute myocardial infarction.

Results - Baseline clinical characteristics did not differ in the groups, except for previous myocardial revascularization surgery, prevalent in the case group (34 patients vs. 12 patients; $p=0.0002)$. This was the only independent predictor of risk for acute myocardial infarction in the postoperative period, based on a multivariate logistic regression analysis $(p=0.0001)$. Mortality and the time of hospital stay of the case group were significantly higher (19.1\% vs. $1.1 \%$; $p<0.001$ and 15.7 days vs. 10.6 days; $p<0.05$ respectively) than those of the control.

Conclusion - Only previous myocardial revascularization was an independent predictor of acute myocardial infarction in the postoperative period, based on multivariate logistic regression analysis.

Key-words: acute myocardial infarction, myocardial revascularization, extracorporeal circulation

Hospital do Coração - ASS.

Mailing address: José Ribamar Costa Jr. - Hospital do Coração - Rua Desembargador Eliseu Guilherme, 123 - 04004-030 - São Paulo, SP - Brazil - E-mail: rmvcosta@uol.com.br
Atherosclerotic coronary disease, in its chronic and acute presentation, is 1 of the 3 major causes of morbidity and mortality in the world ${ }^{1,2}$.

It is estimated that thousands of people are injured or die due to atherosclerotic coronary disease, in addition to the cost of hospital care with this disease ${ }^{1}$.

One treatment of choice for atherosclerotic coronary disease is myocardial revascularization, performed for the first time as an emergency in 1964 by Garret et al $^{3}$, but actually recognized, disseminated, and enhanced with the studies of Favaloro et al ${ }^{4,5}$ at the end of the 1960s.

We believe that in 2001 about 700 myocardial revascularization surgeries were performed all over the world ${ }^{6}$.

Acute myocardial infarction in the postoperative period is one of the possible complications of myocardial revascularization, and its incidence, depending on the criteria adopted to define it, ranges from 4 to $8 \%^{7-11}$. Acute myocardial infarction in the postoperative period increases hospital stay and mortality, involving left ventricular function significantly, contributing to a worse medium- and long-term prognosis of these patients ${ }^{7,8,12,13}$.

This study was performed with the primary purpose of identifying predictor risk factors for acute myocardial infarction in the postoperative period, and had the secondary purpose of assessing its incidence in the referred hospital and its influence on mortality and increased hospital stay.

\section{Methods}

From June 1995 to September 2000, 89 patients undergoing myocardial revascularization at the Hospital do Coração, Associação do Sanatório Sírio, experienced acute myocardial infarction in the postoperative period. We performed a retrospective case-control study paired according to the interval between the surgeries ( \pm 6 months between myocardial revascularization of case and control groups), to age ( \pm 5 years), sex, number and types of grafts [example: 1 
patient who received 1 saphenous vein graft for the circumflex artery and for right coronary arteries, and a left internal mammary artery for the anterior descending artery was paired with another patient who had also received a saphenous vein graft for the circumflex artery, a saphenous vein graft for the right coronary artery and left internal mammary anterior descending artery], to endarterectomy performance (example: one patient in whom endarterectomy was performed in the right coronary artery was paired with another in whom endarterectomy was performed in the right coronary artery), myocardial protection (blood cardioplegy and intermittent aortic cross clamping), and use of extracorporeal circulation.

Acute myocardial infarction in the postoperative period of myocardial revascularization was determined to be when new Q waves occurred (greater than $30 \mathrm{~ms}$ and $0.1 \mathrm{mV}$ ) in one or more eletrocardiographic derivations or when an elevation of the creatine kinase MB fraction activity (CKMB) was more than 3 times above the standard value (10 international units), in the period between the surgical act and the 7 th day of the postoperative period. Electrocardiography was routinely performed in the preoperative period, when the patient arrived at the surgical ward, on the 1st postoperative day, and on the morning of the hospital discharge. CKMB was measured 6 and 12 hours after the end of surgery. When it was more than 3 times above the reference value, serial collection was started to obtain an enzymatic curve.

Possible predictive factors for acute myocardial infarction in the postoperative period were smoking status, dyslipidemia, systemic hypertension, diabetes mellitus, previous acute myocardial infarction, previous myocardial revascularization (performed between 3 and 10 years after the date of the last myocardial revascularization), or previous coronary angioplasties.

The statistical analysis was performed with the chisquare test and adjusting for confounding factors. To estimate relative risk, we used multivariate logistic regression model analysis (where the expert determined the inclusion of the variable to be analyzed in the model). Confidence interval was $95 \%$ and $p$ was significant when $<0.05$.

Information regarding the patients was obtained from the postoperative myocardial revascularization database of the hospital.

\begin{tabular}{|lccc|}
\hline \multicolumn{4}{|c|}{$\begin{array}{c}\text { Table I - Univariate analysis of the possible predictive factors of } \\
\text { acute myocardial infarction in the postoperative period }\end{array}$} \\
\hline $\begin{array}{l}\text { Possible predictor factors } \\
\text { of PAMI evaluated }\end{array}$ & $\begin{array}{c}\text { Case group } \\
(\mathrm{n}=89)\end{array}$ & $\begin{array}{c}\text { Control group } \\
(\mathrm{n}=89)\end{array}$ & $\mathrm{P}$ \\
\hline Dyslipidemia & 42 & 52 & $\mathrm{NS}$ \\
Hypertension & 24 & 27 & $\mathrm{NS}$ \\
$\begin{array}{l}\text { Diabetes mellitus } \\
\text { Smoking }\end{array}$ & 58 & 65 & NS \\
Previous acute & 40 & 33 & NS \\
myocardium infarction & 28 & 23 & NS \\
$\begin{array}{l}\text { Previous angioplasty } \\
\text { Previous myocardium } \\
\text { revascularization surgery }\end{array}$ & 15 & 17 & $\mathrm{NS}$ \\
\hline
\end{tabular}

\section{Results}

In the study period, 3,068 patients underwent myocardial revascularization, and 89 (2.9\%) evolved to acute myocardial infarction in the postoperative period.

Table I shows the univariate analysis of the possible predictive factors of acute myocardial infarction in the postoperative period. In this group, previous myocardial revascularization was present more frequently (34 vs. 12; $\mathrm{p}=0.0002$ ).

The mean time of hospital stay was higher in the cases of acute myocardial infarction in the postoperative period, when compared with that in to the control cases (15 vs. 10 days; $\mathrm{p}<0.05$, fig. 1). Hospital mortality was also higher among patients who experienced acute myocardial infarction in the postoperative period of myocardial revascularization (19.1\% vs. $1.1 \%$; p<0.001, fig. 2 ).

Table II presents the results of the multivariate analysis according to the multiple logistic regression model. In the multivariate analysis of the possible predictors of acute myocardial infarction in the postoperative period, only previous myocardial revascularization surgery was a strong predictor (odds ratio 5.27; confidence interval from 2.35 to $11.82, \mathrm{p}<0.0001)$.

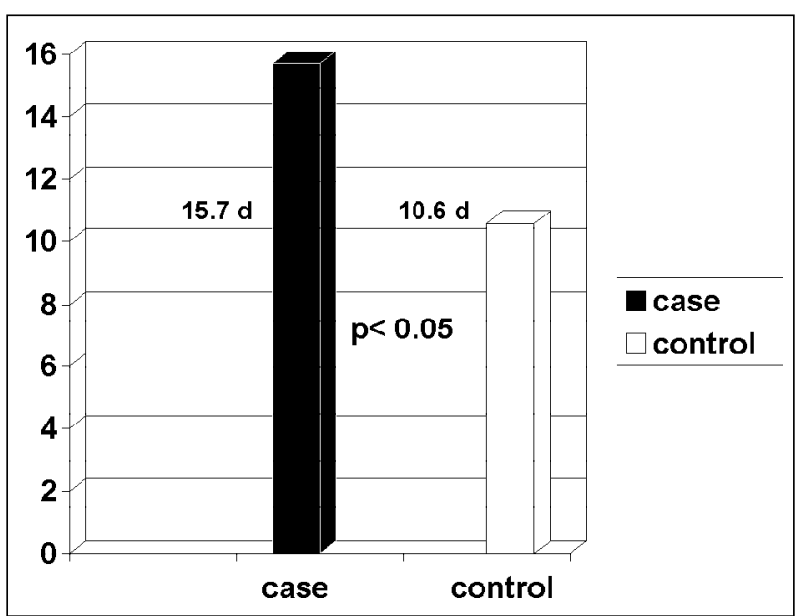

Fig. 1 - Hospital stay.

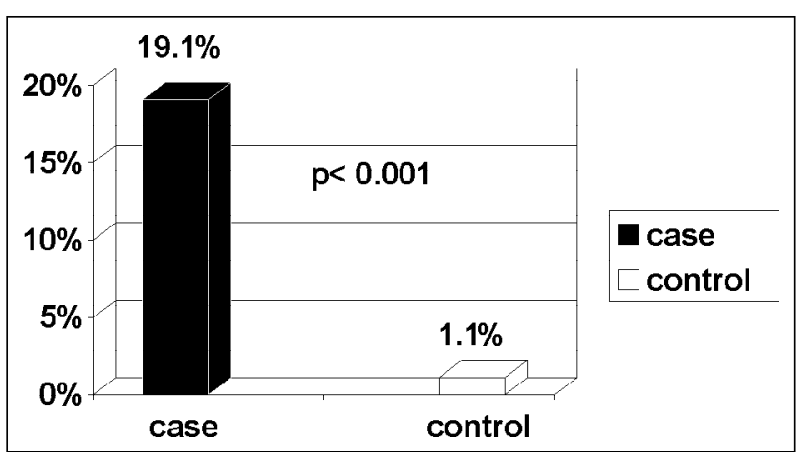

Fig. 2 - In-hospital mortality. 


\begin{tabular}{|c|c|c|c|c|c|}
\hline Risk Factors & Case & Control & Odds ratio & IC of $95 \%$ & $\mathrm{P}$ \\
\hline Dyslipidemia & $47.2 \%$ & $58.4 \%$ & 0.60 & $0.31<\mathrm{OR}<1.13$ & 0.11 \\
\hline Smoking & $44.9 \%$ & $37.1 \%$ & 1.41 & $0.74<\mathrm{OR}<2.66$ & 0.29 \\
\hline Previous ATC & $16.9 \%$ & $18 \%$ & 0.73 & $0.30<\mathrm{OR}<1.74$ & 0.47 \\
\hline Diabetes mellitus & $34.8 \%$ & $27 \%$ & 1.95 & $0.97<\mathrm{OR}<3.91$ & 0.0598 \\
\hline SH & $73 \%$ & $69.7 \%$ & 0.99 & $0.48<\mathrm{OR}<2.02$ & 0.98 \\
\hline Previous MAI & $25.8 \%$ & $31.5 \%$ & 0.75 & $0.36<\mathrm{OR}<1.52$ & 0.42 \\
\hline Previous RM & $38.2 \%$ & $13.5 \%$ & 5.28 & $2.35<\mathrm{OR}<11.82$ & 0.0001 \\
\hline
\end{tabular}

\section{Discussion}

Acute myocardial infarction in the postoperative myocardial revascularization period is a complication that results in worse evolvement in a short- and long-term ${ }^{14-18}$.

Several studies have reported measures that aim at decreasing the incidence of acute myocardial infarction in the postoperative period, in particular enhancement of myocardial protection techniques, enhancement of surgical technique (for example, use of arterial grafts, of circulatory support (especially intraaortic balloon), and pharmacological advances ${ }^{19,20}$.

Several authors ${ }^{10,18,21,22}$ have tried to identify risk factors for acute myocardial infarction in the postoperative period. It is accepted that left main coronary trunk lesion, 3vessel coronary artery disease, ejection fraction lower than $30 \%$, emergency surgery, acute myocardial infarction within less than a week, timing of the clamp release in aortic crossclamping greater than 100 minutes, acute coronary syndrome without ST segment elevation, and previous surgical myocardial revascularization are factors that increase the risk of acute myocardial infarction in the postoperative period.
In this study, risk incidence and hospital mortality were more elevated in those patients with acute myocardial infarction in the postoperative period (19\% vs. $1.1 \%$; $\mathrm{p}<0.0001)$, which is in accordance with data from the literature ${ }^{18,21-23}$.

Among the variables tested as possible risk factors, only the presence of previous myocardial revascularization was identified as an independent predictor of risk. We have pointed out that the mean time of previous infarction in our group of patients was 24 days, and risk factors for atherosclerotic coronary disease tested (dyslipidemia, smoking, diabetes mellitus, and systemic hypertension) were not predictors of acute myocardial infarction in the postoperative period of myocardial revascularization.

We also observed increased hospital stay in the case group in comparison with that of the control.

Based on these results, we concluded that acute myocardial infarction in the postoperative period after myocardial revascularization surgery results in greater hospital mortality; however, in this study it was a low-incidence complication, and the previous myocardial revascularization was the only predictor of risk.

\section{References}

1. WHO - MONICA Project: myocardial infarction and coronary deaths in the World Health Organization Monica Project: registration produces, events rates and case-fatality rates in 38 populations from 21 countries in four continents. Circulation 1994; 90: 583.

2. Maseri A. Ischemic Heart Disease. New York: Churchill Livingstone, 1995 $713 p$.

3. Garret HE, Dennis EW, Debakey ME. Aortocoronary bypass with saphenous vein graft: seven-year follow-up. JAMA 1973; 223: 792.

4. Favaloro RG. Saphenous vein autograft replacement of severe segmental coronary artery occlusion: operative technique. AnnThorac Surg 1968; 5: 334

5. Johnson WD, Flemma RJ, Lepley LD, et al. Extended treatment of severe coronary artery desease: a total surgical approach. Ann Surg 1969; 170: 460

6. Stone G. In: Transcatheter Cardiovascular Therapeutics, 2001.

7. Namay DL, Zia MS, Dodge HT, Namay K. Effect of perioperative myocardial infarction on late survival in patients undergoing coronary artery bypass surgery. Circualation 1982; 65: 1066-71.

8. Chaintman BR, Alderman EL, Sheffield LT, et al. Use of survival analysis to determine the clinical significance of new $\mathrm{Q}$ waves after coronary artery bypass surgery. Circulation 1983; 67: 302-9.

9. Iyer VS, Russell WJ, Leppard P, et al. Mortality and myocardial infarction after coronary artery surgery. Med J Aust 1993; 159: 166-70.

10. Antman EM, Collins Jr JJ, Rizzo RJ. Current incidence and determinants of perioperative myocardial infarction in coronary artery surgery. Am Heart J 1996; 132: 572-8.
11. Serruys WP, Sousa JEMR, Jatene AD, et al. Comparison of coronary artery bypass surgery and stenting for the treatment of multivessel desease. N Engl J Med 2001; 344: 1117-24.

12. Myers WD, Davis K, Foster ED, et al. Surgical survival in the coronary artery surgery study registry. Ann Thorac Surg 1985; 40: 245-60.

13. Force $\mathrm{T}$, Kemper AJ, Bloomfield $\mathrm{P}$, et al. Non-Q wave perioperative myocardia infarction: assessment of the incidence and severity of regional dysfunction with quantitative two-dimensional echocardiography. Circulation 1985; 72: 781-9.

14. Guiteras VP, Pelletier LC, Hernandez MG, et al. Diagnostic criteria and prognosis of perioperative myocardial infarction following coronary bypass. J Thorac Cardiovasc Surg 1983; 86: 878-86.

15. Burton JR, FitzGibbon GM, Keon WJ, et al. Perioperative myocardial infarction complicating coronary bypass: Clinical and angiographic correlations and prognosis. J Thorac Cardiovasc Surg 1981; 82: 758-64

16. Force T, Hibberd P, Weeks G, et al. Periopaerative myocardial infarction after coronary artery bypass surgery: Clinical significance and approach to risk stratification. Circulation 1990; 82: 903-12.

17. Stahle E, Bergstroom R, Holmberg L, et al. Risk factors for operative mortality and morbidity in patients undergoing coronary artery bypass surgery for stable angina pectoris. Eur Heart J 1991; 12: 162-8.

18. Svedjeholm R, Olin C, Dahlin LG. Perioperative Myocardial Infarction in Cardiac Surgery: Risk Factors and Consequences - A Case Control Study. Scan Cardiovasc J 2000; 34: 522-7.

19. Buckberg GD. Strategies and logic of cardioplegic delivery to prevent, avoid 
and reverse ischemic and reperfusion damage. J Thorac Cardiovasc Surg 1987; 93: $127-39$

20. Ovrum E, Abdelnoor M, Forfang K. Effect of aortic cross-clamp time on myocardial infarction after coronary bypass surgery. Asian Cardiovasc Thorac Ann 1997; 5: 77-82.

21. Weintraub WS, Jones EL, King SP III, et al. Changing use of coronary angioplasty and coronary bypass surgery in the treatment of chronic coronary artery disease. Am J Cardiol 1990; 65: 183-8.

22. Sanz G, Pomar LJ, Bosch X, et al. Predictors of Early Saphenous Vein Aortocoronary Bypass Graft Occlusion. Ann Thorac Surg 1993; 56: 1101-6.

23. Dargie HJ, Lip GYH, Metcalfe MJ. Factors Influencing coronary artery bypass graft patency. Cardiovasc Surg 1994; 6: 679-84. 